\title{
Effect of Organic Matter Amendment on Hydraulic and Pore Characteristics of a Clay Loam Soil
}

\author{
Moniruzzaman Khan Eusufzai ${ }^{1,2 *}$, Katsumi Fujii ${ }^{1}$ \\ ${ }^{1}$ Faculty of Agriculture, Iwate University, Morioka, Japan; ${ }^{2}$ Department of Geotechnical and Environmental Science, River Research \\ Institute, Dhaka, Bangladesh. \\ Email: *mzk1973_82@hotmail.com
}

Received May $17^{\text {th }}, 2012$; revised June $20^{\text {th }}, 2012$; accepted July $10^{\text {th }}, 2012$

\begin{abstract}
The objective of this study was to examine the effect of compost, rice straw and sawdust amendment on hydraulic and pore characteristics of a clay loam soil. Amendments were applied at an application rate of $0.2 \mathrm{~m}^{3} / \mathrm{m}^{3}$ (apparent soil volume) in three rectangular plots each comprising an area of $3.0 \mathrm{~m}^{2}$. Water retention characteristics were measured by hanging water column and centrifuge method. Hydraulic conductivity was measured by disc permeameter at -15.0 , $-6.0,-3.0$ and $0 \mathrm{~cm}$ of water pressure heads. Volumetric water content increased in all amended soils, compared with the control. Unsaturated hydraulic conductivity was almost identical for straw and sawdust at all pressure heads, although that for compost amended soils were much higher. Field saturated hydraulic conductivity $\left(K_{f s}\right)$ was higher in organic matter amended soils as were number of macropores $(14.7 \%-29.2 \%)$. Contribution of each pore class to the total saturated flux was evaluated from the hydraulic conductivity and water retention measurement. A new alternative weighed factor $\left(W_{e}\right)$ was proposed to estimate the actual contribution of macro- and mesopores to the total saturated water flux. The $W_{g}$ was found to be more representative for calculating pores contribution to saturated water flux than that of hydraulic conductivity measurement. Although there is only a small fraction of the total porosity, amendment increased effective macro- and meso-porosity $\left(\theta_{\varepsilon}\right)$. Pores in the amended soils were hydraulically active and water movement was dominated by gravity. Collectively, our results demonstrated that organic matter generated as agricultural by-product could effectively be used to improve soil quality.
\end{abstract}

Keywords: Organic Matter; Hydraulic Conductivity; Volumetric Water Content; Saturated Water Flux; Porosity

\section{Introduction}

Field scale measurement of soil hydraulic properties including quantification of porosity are very important in organically managed soil. Hydraulic conductivity and soil porosity are the two most important properties regulating water movement and storage of air and water available to plants. Application of fresh and composted crop and plant biomass, therefore, is often recommended as a viable option to maintain good soil tilth compared with mineral fertilizers. Organic matter itself plays a dominant role in soil aggregation by increasing organic carbon [1], which increases the macro porosity and then improves water infiltration [2]. A number of studies have been reported on the effects of farmyard manure on soil structure and hydraulic properties [3-6]. Some of these studies have reported that application of manure increases the saturated hydraulic conductivity $\left(K_{\text {sat }}\right)$ and infiltration rate [7-9]. On the other hand some studies did not find any

\footnotetext{
*Corresponding author.
}

effect on $K_{\text {sat }}$ after initial wetting, but find a positive effect after two to five wet-dry cycles [10]. Very few studies have measured unsaturated hydraulic conductivity in organic matter amended soils $[11,12]$. Especially we did not find any study that measured unsaturated hydraulic conductivity in compost, straw and sawdust amended soil.

Porosity and pore-size distribution determines the rate and movement of air and water into the soil [13]. Macropore favors the high infiltration rate, good tilth, and adequate aeration for plant growth [13]. A better knowledge and quantification of infiltration and water movement in macroporous soil is therefore very important. Few studies have reported the effect of pore size distribution due to manure addition into soil [14-16]. However, most of these studies are either limited to manure amendment effects on soil macroporosity [15] or pore size distribution [14]. None of the studies have reported the effect of organic matter amendment on functional characteristics of soil porosity, which is very important considering the water movement. Furthermore, the effect 
of organic matter incorporation on hydraulic properties is often neglected when simulating water flow in agricultural fields. Characterization of these properties at field scale is a challenging task because of their transient nature and lack of appropriate measurement techniques [17]. For the last decades, disc permeameter has become a valuable tool for measuring the saturated and near saturated soil hydraulic properties. Disc permeameter measurements make it possible to calculate hydraulic conductivity, sorptivity and soil porosity from cumulative water infiltration with minimal disturbance of soil.

The objective of this study was to characterize the hydraulic and pore characteristics of organic amended soil. To this end, measurements of soil hydraulic conductivity using disc permeameter technique and the corresponding water conductive pore analysis were performed in clay loam soils amended with compost, rice straw and sawdust in an upland fallow field in the northeastern Japan.

\section{Materials and Methods}

\subsection{Unsaturated and Field Saturated Hydraulic Conductivity}

\subsubsection{Theory}

The steady state flow theory is based on the [18] semianalytical solution, which approximates steady state flux density $\left(\mathrm{LT}^{-1}\right)$ from a circular disc of radius $r_{d}$ as

$$
q_{0 \infty}=K_{0}+\frac{4 \phi_{0}}{\pi} \frac{1}{r_{d}}
$$

where $\phi_{0}$ is the matrix flux potential and is defined by

$$
\phi_{0}=\int_{h n}^{h o} K(h) \mathrm{d} h h_{n} \leq h_{o} .
$$

Following the [19] $K(h)$ relation for quasi-linear soil:

$$
K(h)=K_{s} \exp (\alpha h)
$$

where $K_{s}$ is the saturated hydraulic conductivity and $\alpha$ is a fitting parameter $\left(\mathrm{cm}^{-1}\right)$ and

$$
\phi=\frac{K}{\alpha} \text {. }
$$

In Equations (1) and (2), $K_{o}$ is the hydraulic conductivity at applied pressure head, $h_{o}$, i.e. $K_{o}=K\left(h_{o}\right)$. The subscripts $n$ and $o$ refers to the initial and final surface boundary condition. The first term in the right hand side of Equation (1) is the hydraulic conductivity accounts for the effect of gravity and the second term is the effects of capillary sorptivity, $S=S\left(h_{o}\right)$. Wooding's solution (Equation (1)) for steady state infiltration from a circular source can be written in the form $[20,21]$;

$$
Q s=\left(\frac{a}{G d}+\pi a^{2} \alpha\right) \phi_{o} ; a>0,
$$

where $Q_{s}$ is the steady state flow rate $\left(\mathrm{L}^{3} \mathrm{~T}^{-1}\right) ; \alpha$ is disc radius (L), $G d$ is dimensionless shape factor (assumed as $0.25), \alpha$ is sorptive number $\left(\mathrm{L}^{-1}\right), \phi_{0}$ is matrix flux potential $\left(\mathrm{L}^{2} \mathrm{~T}^{-1}\right)$. Here $\alpha$ is defined by

$$
K(h)=K_{f s} \exp (\alpha h) ; 0<\alpha<\infty ;-\infty<h \leq 0 .
$$

The analysis of disc infiltrometer data based on Equation (5) requires two or more steady state flow values for a single disc radius at different pressure heads [20-22]. Hydraulic conductivity and sorptive number $\alpha\left(\mathrm{L}^{-1}\right)$ is estimated from the Gardner's exponential model (Equation (6)) assumed that $\alpha$ is constant over the entire range of applied pressure head, h. Ankeny et al. (1991) [21] proposed that the sorptive number $\alpha$ in Equation (6) is constant over the interval between two adjacent supply pressure heads, i.e. piecewise linear instead of entire range of applied pressure heads. Therefore $K(h)$ over the range of $-\infty<h \leq 0$ can be estimated as piecewise exponential relationship of the form

$$
K(h)=K_{i, i+1} \exp \left(\alpha_{i, i+1} h\right) i=1,2,3 \cdots
$$

where, $\alpha_{i, i+1}$ and $K_{i, i+1}$ are the piecewise slope and intercept of a linear plot of $\ln (Q s)$ and $h$ for the entire range of applied pressure heads.

\subsubsection{Water Conductive Porosity}

In classical capillary rise theory; it is assumed that the soil matrix is composed of bundle of straight capillary tube. If the capillary tubes remain full of water under an applied pressure head $h$, the maximum equivalent pore radius, $r$ is defined as

$$
r=-\frac{2 \sigma}{\rho g h} h<0
$$

where $\sigma\left(\mathrm{g} / \mathrm{s}^{2}\right)$ is the surface tension of water, $\rho\left(\mathrm{g} / \mathrm{cm}^{3}\right)$ is the density of water, and $g\left(\mathrm{~cm} / \mathrm{s}^{2}\right)$ is the acceleration due to gravity. We defined macropores as those pores drained at $h>-3 \mathrm{~cm}(r>0.50 \mathrm{~mm}$, [23] and mesopores-I (draining at $h>-6$ i.e., $0.50>r>0.25 \mathrm{~mm}$ ) and mespores-II $(h>-15 \mathrm{~cm}$ i.e., $0.25>r>0.10 \mathrm{~mm})$. Combining the Poiseuille's law and capillary rise equation [23], defined the maximum number of effective macropores per unit area, $N$, as

$$
N=\frac{8 \mu\left(K_{i}-K_{i-1}\right)}{\rho g \pi r^{4}} i=1,2,3, \cdots, n
$$

where $\mu$ is the viscosity of water $\left(\mathrm{g} / \mathrm{cm}^{1} / \mathrm{s}^{1}\right), \rho$ is the density of water $\left(\mathrm{g} / \mathrm{cm}^{3}\right)$ and $r$ is the minimum pore radius for the given pressure head range. The effective porosity $\left(\theta_{\varepsilon}\right)$ is then given by

$$
\theta_{s}=N \pi r^{2}
$$

The underlying assumptions in Equation (9) are that, flow is laminar and pores are completely full, so the 
tortuosity and pore necks are insignificant. Because of these assumptions, the resulting $N$ is equivalent not to an actual number of macropores.

The contribution of each pore class to the total saturated water flux, $Q_{f}(\%)$ can be calculated by [24]:

$$
Q_{f}(\%)=\frac{K\left(h_{i}\right)-K\left(h_{i-1}\right)}{K\left(h_{0}\right)} \times 100 i=1,2, \cdots, n
$$

where, $i$ is the number of measurement performed in a sequence, $h$ is applied pressure head, $K\left(h_{i}\right)$ and $K\left(h_{i-1}\right)$ the hydraulic conductivity of the two consecutive pressure heads, and $K\left(h_{0}\right)$ is the saturated hydraulic conductivity.

The actual contribution of each pore class to total flow can be calculated from the water retention measurement. Considering the minimum equivalent radius $\left(r_{e}\right)$ of each pore size range, we propose a new weighed factor $\left(W_{e}\right)$. The proportion of water flux actually moving through each pore class, $W_{e}(\%)$ can be expressed by:

$$
\frac{\theta\left(h_{i}\right)-\theta\left(h_{i-1}\right)}{\sum \Delta \theta \times r_{e}^{2}} \times r_{e}{ }^{2} \times 100 i=1,2,3, \cdots n
$$

where, $i$ is the number of pore class under consideration, $\theta\left(h_{i}\right)$ and $\theta\left(h_{i-1}\right)$ is the volumetric water content for two consecutive pressure heads in the drying curve of water retention measurement, $\Delta \theta$ is the difference in volumetric water and $r_{e}$ is the equivalent pore radius for the respective pressure heads.

\subsubsection{Characteristics Mean Pore Radius}

Capillarity and gravity combined with water source geometry dictate the pattern and flux of water entry into soil during 3-dimensional infiltration from disc permeameter [25]. Characteristics mean pore radius $\left(\lambda_{m}\right)$ and macroscopic capillary length $\left(\lambda_{c}\right)$ can be used to describe such a water flow [26]. Where,

$$
\begin{aligned}
\lambda_{c} & =\frac{1}{\alpha} \\
\text { and } \lambda_{m} & =\frac{\sigma}{\rho g \lambda c}
\end{aligned}
$$

$\lambda_{c}$ is flow weighted mean soil water potential $\left(\mathrm{L}^{-1}\right)[27]$ and $\lambda_{m}(\mathrm{~L})$ is a useful measure of soil structure.

\subsection{Experimental Site}

The site is located at the Iwate University Experimental Station, in the prefecture of Iwate, the northeastern part of Japan. The climate is cold with an average annual precipitation of $1516 \mathrm{~mm}$ and an average annual air temperature of $10.9^{\circ} \mathrm{C}$. The soil at the experimental site is volcanic ash soil, Andisol and clay loam in texture (43.8\% sand, $42.1 \%$ silt and $14.1 \%$ clay). Basic soil characteristics were as follows: particle density $2.6 \mathrm{Mg} / \mathrm{m}$; bulk density $1.20 \mathrm{Mg} / \mathrm{m}^{3}$; total cabon $106 \mathrm{~g} / \mathrm{kg}$ and total ni- trogen $1.68 \mathrm{~g} / \mathrm{kg}$ (dry weight basis). Organic matter namely; compost, sawdust and fresh rice straw were applied on a random basis in three rectangular plots each comprising an area of 3.0 sq. meter. Another plot was prepared as control plot for measurement and result comparison purpose. Organic matter was applied at an application rate of $0.2 \mathrm{~m}^{3} / \mathrm{m}^{3}$ of apparent soil volume, which corresponded to an incorporation depth of $0.15 \mathrm{~m}$. Amendments were done in the middle of July 2005 to these plots and incorporated to a depth of $0.15 \mathrm{~m}$ by a small tractor implemented with a rotavator. Control plot was also tilled to the same depth as the treatment plots to avoid the confounding effects of tillage. Compost used in this study was a mixture of rice straw, cow excrement and wood bark. Sawdust obtained from a lumber mill was predominantly Japanese cedar waste. Water content and particle density of compost and sawdust was 0.75 $\mathrm{kg} / \mathrm{kg}, 2.70 \mathrm{Mg} / \mathrm{m}^{3}$ and $0.43 \mathrm{~kg} / \mathrm{kg}, 1.71 \mathrm{Mg} / \mathrm{m}^{3}$, respectively. Rice straw (Japonica) was collected from the farm at Takizawa, a neighboring village of Morioka, Iwate, Japan. Straw was air dried and cut into $1-2 \mathrm{~cm}$ pieces. Water content and particle density of rice straw were $0.19 \mathrm{~kg} / \mathrm{kg}$ and $1.60 \mathrm{Mg} / \mathrm{m}^{3}$.

\subsection{Experimental Measurements}

The soil hydraulic properties were characterized at each treatment and control plots using a disc permeameter of [28] type with a base radius of $20 \mathrm{~cm}$ (Endo Rika Co. Ltd., Japan). The experiment was performed from May to June 2007. To consider only the effects of biomass amendments on soil water infiltration, the surface crust, clods and grasses were removed from the soil surface. To ensure good hydraulic contact between the disc and the soil, a thin layer of commercial sand, was also poured onto the soil surface. The base of the disc was covered with a nylon cloth of $20-\mu \mathrm{m}$ mesh. Infiltration runs were performed at four values of Pressure heads, $h$ (namely, $-15.0,-6.0,-3.0$ and $0 \mathrm{~cm}$ of water, applied in this order and at the same place). Therefore, three classes of pore ranges were defined: pores with equivalent radius greater than $0.50 \mathrm{~mm}$ (macropores), between 0.50 and $0.25 \mathrm{~mm}$ (mesopores 1) and between 0.25 to $0.10 \mathrm{~mm}$ (mesopores 2). For each plot three replicate sequences of infiltration runs were performed. Flow monitoring continued until the steady state from the disc was attained. The flow readings were manually recorded from the drop in the water level of the water supply reservoir of the infiltrometer at a preset time step of every $30 \mathrm{~s}$ for few initial readings and there after every 5 minutes at the end of each run. The antecedent soil moisture was measured from the disturbed soil sample collected in triplicate for each treatment plots on the same day as infiltration measurement. At the end of each sequence of infiltration run, small volume of disturbed soil sample was collected 
directly below the disc to measure the saturated soil moisture. Volumetric soil water content $(\theta)$ was determined from gravimetric soil moisture (oven drying the soil at $105^{\circ} \mathrm{C}$ ) and the known bulk density for each treatment and control plots. The soil hydraulic conductivity, $K$ for at different pressure heads were thus calculated from the steady state infiltration rate using the multiple-pressure head approach [21].

At the end of infiltration experiment, undisturbed soil samples were collected from all treatment and control soils by core sampler of $5.1 \mathrm{~cm}$ length and $5.0 \mathrm{~cm}$ diameter. The samples were saturated from bottom for $24 \mathrm{~h}$. In the hanging water column the saturated samples were put on a saturated porous plate whose bottom was in contact with a water column. Then, the samples were equilibrated with suction imposed by a water column height of $-4.5,-50.0$ and $-96.0 \mathrm{~cm}$. The samples remained $3 \mathrm{~d}$ at each equilibrium stage and weighed. There after the samples were extracted using the following pressures: -501 , -1000 and $-2513 \mathrm{~cm}$ of water by high-speed centrifuge. Pressure heads of $-3.16 \times 10^{5}$ and $-1.0 \times 10^{7} \mathrm{~cm}$ were taken as air dry and oven dry condition. Volumetric water content at perfectly saturated condition $(0.0 \mathrm{~cm}$ of water pressure head) was estimated from the three-phase composition, assuming all pores are fully saturated, i.e. volume of air equals to zero. The changes in air, water and gas phase in the soil matrix after the incorporation of compost, straw and sawdust were estimated from the collected undisturbed soil cores.

Approximately $1.0 \mathrm{~cm}$ of the topsoil was scraped and one undisturbed core was taken at the top $6 \mathrm{~cm}$ soil depth for each plot. Disturbed soil samples were also collected at the same time for gravimetric water content measurements. Collected samples were weighted immediately and were oven-dried for determining the solid mass. The mass of solid, water and amendments were estimated for 100 c.c total soil sample using the average water content obtained from disturbed soil samples. This mass weight was converted to volume proportion of solid, water and organic amendments by using the particle density of soil amendments mixture. Subtracting the volume of solid, water and amendments from the total sample volume of $100 \mathrm{~cm}^{3}$ resulted in an estimate of the gas phase volume. The volume proportion of solid, water, gas and amendments was then converted into percentage.

\section{Results and Discussion}

\subsection{Soil Water Retention}

Water retention characteristics of compost, straw and sawdust incorporated soils at different pressure heads are presented in Figure 1. The results showed that, at most or all imposed pressure heads water retention characteristics of amended soil had generally increased. At the same water pressure head, soils amended with sawdust had higher retention ability than compost and straw. For example, volumetric water content of sawdust incorporation increased by $0.171,0.035,0.034$ and $0.035 \mathrm{~m}^{3} / \mathrm{m}^{3}$ at $-4.50,-50.1,-96.0$ and $-1000 \mathrm{~cm}$ of water pressure head compared to the control. At the same imposed pressure head, compost and straw amended soil retained less amount of water than sawdust. The increment of saturated water content in sawdust amended soil was larger by an order of magnitude than those of compost and straw.

The improvement of water content at higher-pressure head in the organic matter amended soils, presumably resulted from the increased total porosity. The porosity expansion in the amended soil was very much evident from the phase composition analysis of the soil matrix (Figure 2). For example, incorporation of compost and sawdust at $0.2 \mathrm{~m}^{3} / \mathrm{m}^{3}$ application rate increased the saturated porosity (at $0.0 \mathrm{~cm}$ pressure head) by 2.35 and $3.81 \%$ compared with the control soils. In contrast, at the same application rate straw incorporation decreased the porosity by $0.71 \%$. Water retention at higher potential primarily depends upon capillarity and pore size distribution, while water retention at lower potential is due mainly to surface adsorption [29]. Assuming the pores as the bundle of capillary tube, the equivalent pore radius $\left(r_{e}\right)$ was calculated from the Young-Laplace equation of capillary rise theory such that $r_{e}$ at $-4.50,-50.1,-96.0$ $\mathrm{cm}$ of water pressure heads were $0.330,0.030,0.015 \mathrm{~mm}$, respectively. However, at very low pressure head such as $-3.16 \times 10^{5} \mathrm{~cm}$, the $r_{e}$ drops down to $2.35 \mathrm{~nm}$, which is not an actual capillary size but a surface adsorption scale that forms a hydration envelop over the particle surface. The soil in this study was clay loam in texture, thus the incorporation of organic matter develops fine pores of nm scales.

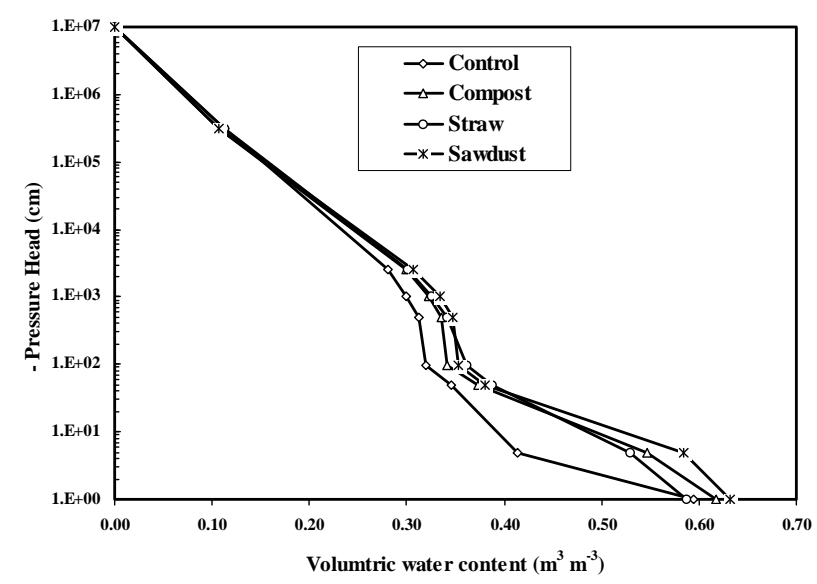

Figure 1. Water retention curves of compost, straw and sawdust amendment with clay loam soil expressed as a function of volumetric water content. 


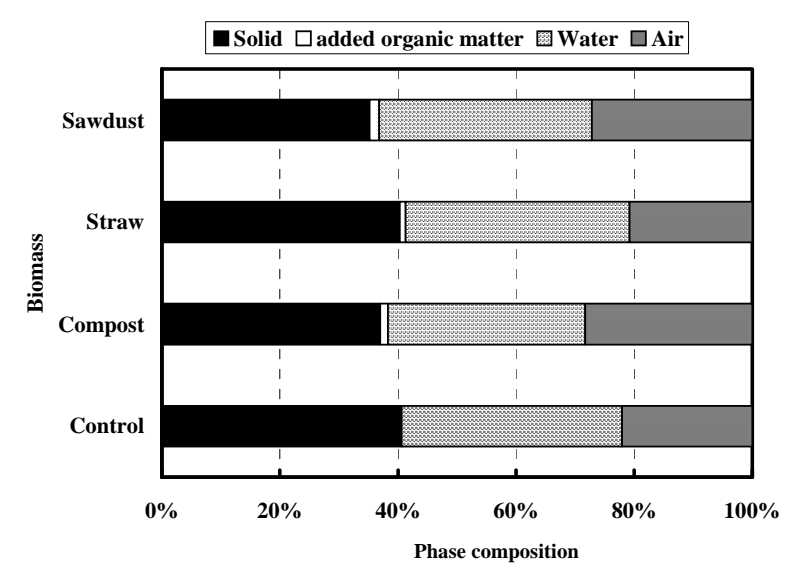

Figure 2. Changes in the phase composition of soil matrix in organic biomass amended soils.

\subsection{Hydraulic Conductivity}

Application of organic matter showed a substantial effect on hydraulic conductivity at near saturated condition. The average value of the soil hydraulic conductivity $(K)$ at different pressure heads for treatments and control soil is illustrated in Figure 3. Incorporation of organic matter increased $K$ in amended soils at all pressure heads, except for straw at $-15 \mathrm{~cm}$ compared with the nonamended soil. At any pressure head, organic matter amendment effect on $K$ was more obvious in compost-amended soil, than straw and sawdust. For example, field saturated conductivity, $K_{f s}$, was increased by $34.4 \%$ for compost and $15.9 \%$ for straw and sawdust amended soils relative to the control. The increase of $K_{f s}$ with the addition of compost, straw and sawdust may be associated with the increase of soil aggregation and macro porosity. Although we did not measure soil aggregation, but calculation of macro- and meso-porosity enables us to draw the above proposition, which we discussed in the following sections. Unsaturated hydraulic conductivity, $K(h)$, rose up almost three order by increase of pressure from -15 to 0 $\mathrm{cm}$ for all treatments and control soils. The large increase in $K$ over the small increase in pressure head indicates that extensive macropore networks exist in the organic matter amendment soils. The effect of straw and sawdust amendments on unsaturated hydraulic conductivity, $K(h)$ were similar at all three pressure heads compared with the control soils.

However, compost incorporation had a greater effect on $K(h)$ compared with straw and sawdust. The average $K(h)$ increased by $47.2,99.1$ and $256 \%$ at $-15,-6$ and -3 $\mathrm{cm}$ water pressure head, respectively, for compost amended soils compared to the control soils. We assumed that the lack of response of $K(h)$ for straw and sawdust incorporation at these pressure heads may be due to the increased tortousity. The addition of straw and sawdust created a hydraulic discontinuity with empty pores that reduced the cross sectional area of soil participating in the water movement in unsaturated condition. The obscurity of response $K(h)$ with the addition of straw and sawdust is consistent with other studies where there were no or little effect of $K(h)$ on manure [30] and cheese-whey [12] amended soils.

\subsection{Pore Class Contribution to the Flow}

Pore classes' contribution to the total saturated water flux was calculated from the steady-state infiltration data obtained from the infiltration experiment and according to the Equation (11).

The results of $Q_{f}$ are shown in Figure 4. On average and regardless of treatment effect, macropores accounted for $94 \%$ of the total saturated water flux and the remaining $6 \%$ by the mesopores. Contribution of each pore class to the saturated water flux was observed variable among treated soils. Percent of water flux through pores $>0.50 \mathrm{~mm}$ for compost, straw and sawdust incorporated soils either remained constant or decreased, while that through pores $>0.25 \mathrm{~mm}$ increased compared with control soils. Pore classes' contribution was computed as the ratio of increment in hydraulic conductivities between two consecutive pressure heads to the total saturated water flux. Thus, the flow through macro- and mesopores estimated by Equation (11) is not an actual flow rate, rather a fraction to the total flow assuming total flow as unity.

Therefore, we calculated an alternative index $\left(W_{e}\right)$ from the water retention data (Equation (12)) that may be more representative to the actual contribution of the pores to the total flow. The results of this new index $W_{e}$ for estimating contribution of macro- and mesopores to the saturated flow are presented in Figure 5. The $W_{e}$ was

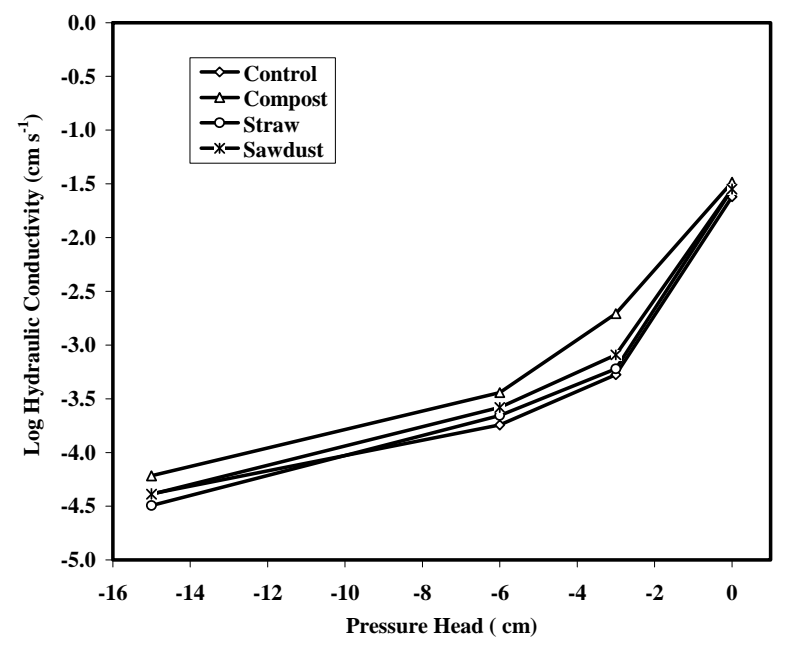

Figure 3. Mean values of $\log _{10} K$ for Control, compost, straw and sawdust incorporated soils. Vertical bars are standard deviations of the mean. Treatment levels are defined in materials and methods. 


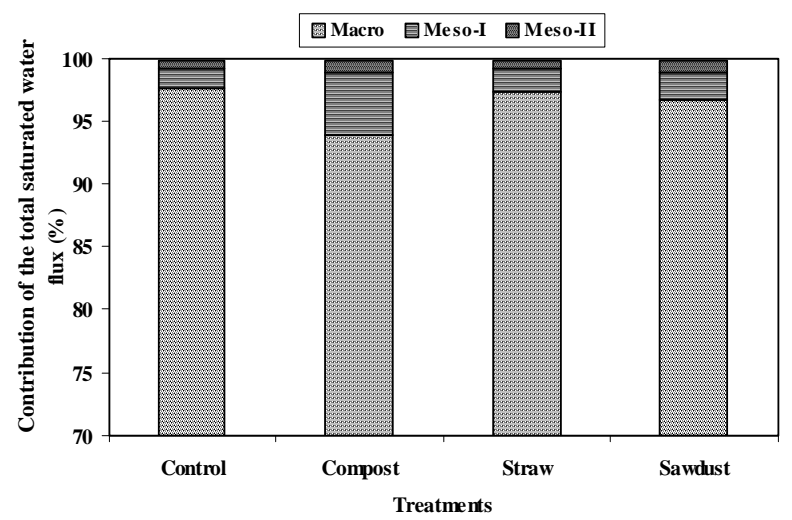

Figure 4. Pore classes' contribution to the total saturated water flux (\% of total flow) in each organic matter amended soils. Saturated water flux was measured at the surface soil $(0$ - 5 cm).

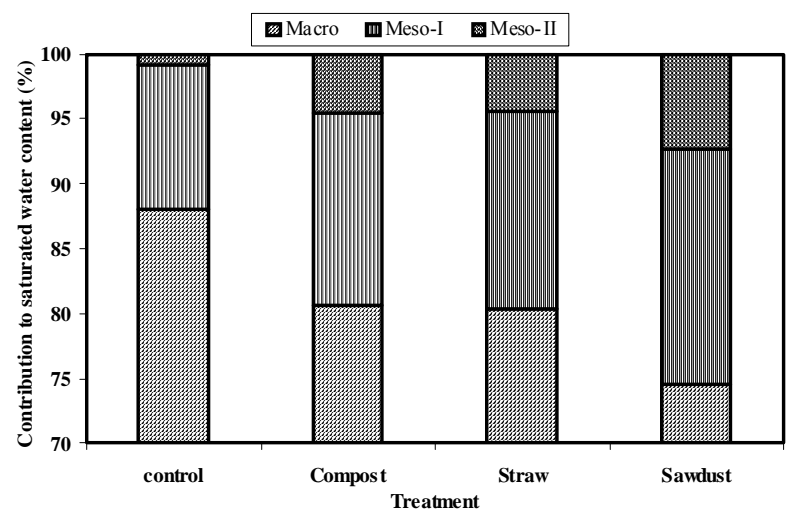

Figure 5. Contribution of the pores to the saturated water content measured from water retention characteristics of treatments and control soils. Treatment levels are defined in materials and methods.

greater in non amended soil $(88.0 \%)$ than that observed for compost (80.6\%), straw (80.4\%) and sawdust (74.6\%) amended soils. In contrast, the contribution of the mesopore-I to the total saturated water flux in compost $(15.0 \%)$, straw $(15.1 \%)$ and sawdust $(18.1 \%)$ was higher than that estimated for control soils $(11.3 \%)$. The similar trend was observed for mespores-II contribution to the total water flow. On average and regardless of treatments effect, macropore contribution to the saturated water flux was lower (74.6\%), while that for mesopores was higher (25.4\%) estimated by $W_{e}$ than $Q_{f}$ estimated by Equation (11).

The remarkable difference between these two Figures (Figures 4 and 5) exemplifies the significant role of macropores to the saturated water movement. The flow process participating in the quantification method may be better explained by the macro- and mesopores role to the water flow. Figure 4 was drawn on the basis of cumulative infiltration data obtained by disc permeameter. The quasi-steady state condition in the infiltration experi- ments prevailed only several minutes at near saturated condition. Data acquired under such condition is rather dubious because of uncertainty of steady state condition of short run time. Therefore, pores of smaller size, such as, mesopores can't be perfectly filled by the infiltrating water. Perhaps this leads to the underestimation of mesopores contribution in Figure 4. In contrary, Figure 5 was illustrated from the water retention data, which is a slow drainage process and requires several days to reach in equilibrium condition. Therefore, it may be assumed that all pores are ideally saturated and then drained. The advantage of $W_{e}$ over that estimated by Equation (11) is the elimination of possible underestimation of mesopores contribution and estimation of actual contribution of each pore class to the saturated water flux instead of unit flux assumption. However, $W_{e}$ should be used in caution as ideal saturation of all pores during the slow drainage process may require much longer time. We may thus conclude that the soil water movement through macro and mesopores may be better characterized by using the $W_{e}$ instead of the hydraulic conductivity data (Equation (11)).

\subsection{Soil Macro and Mesoporosity}

The number of pores per unit area $(\mathrm{N})$ calculated with Equation (9) for different pore size classes and treatments soil are presented in Table 1. The number of pores in amendment treatments and control soils varied from 989 to $1278 / \mathrm{m}^{2}$ (>0.5 mm diam.), 247 to $1073 / \mathrm{m}^{2}$ (0.25 - 0.50 $\mathrm{mm})$ and 3741 to $8005 / \mathrm{m}^{2}$ (0.10 - $\left.0.25 \mathrm{~mm}\right)$. Within each pore class, the minimum values were obtained for control soils. The largest numbers of pores per unit area were observed for pore class of mesopores-II $(0.25>r>0.10$ $\mathrm{mm})$. Compost, rice straw and sawdust incorporation increased average number of effective water conducting macropores by $29.2 \%, 15.4 \%$ and $14.8 \%$, respecttively compared with the control. Among the all three treatment soils, the numbers of pores per unit area of all classes' were largest in compost amended soils compared with other treatments. The amendment effect on macro pore evolution was like Compost $>$ Straw $>$ Sawdust. Pore size class of mesopores-I $(0.50>r>0.25 \mathrm{~mm})$ per

Table 1. Average number of effective macro- and mesopores per square meter. Treatment levels are defined in materials and methods. All values are average of three replicates.

\begin{tabular}{cccc}
\hline Treatment & Macro & Meso-I & Meso-II \\
\hline Control & 989 & 247 & 3741 \\
Compost & 1278 & 1073 & 8005 \\
Straw & 1142 & 345 & 5416 \\
Sawdust & 1135 & 427 & 6294 \\
\hline
\end{tabular}


unit area was highest for compost amended soil, followed by sawdust and straw amendment. Similar to the mesopores-I, amendment of compost, straw and sawdust also increased the number of mesopores-II. Organic matter incorporation resulted in the largest increase of this smallest size pores per unit area in all treatments and control soils. Number of mesopores-II for compost, straw and sawdust amended soils increased by $113.9 \%, 44.7 \%$ and $68.2 \%$, respectively, compared with the non-amended soils. Al- though, amendment of compost, straw and sawdust did not increase the macropores at higher percentage, but lead the substantial increase of $K_{f s}$ (Figure 3).

Organic matter increases the proportion of larger pores [31]. These macropores are the dominant pathway of channel flow through the soil from surface ponding [32]. It is indicated from our study that regardless of treatment effect, most of the total saturated water flux (Figures 4 and 5) occurred through macropores. The increase of water transmitting macro- and mesoporosity can be explained by the change of phase composition of the soil matrix due to biomass addition (Figure 2). Addition of compost, straw and sawdust reduced the solid phase and increased the air phase compared with non-amended soils. This reduction of solid phase may increase inter- and intra-aggregate spaces, which are responsible for increase in water transmission and storage pores. These cylindrical pores are very important in the separation of precipitation from runoff and infiltration [2]. Application of compost, straw and sawdust remarkably increased the number of small pores, i.e., the pore class mesopores-I and mesopores-II compared with the non-amended control soils. These mesopores are also important for drainage, wetting-drying, and movement of soil water under gravitation [23]. The literature on characterization of soil porosity in relation to organic matter is scarce. Higher permeability and continuity of pore systems in a straw incorporated soil were also observed by [33]. However, characterization of soil porosity in relation to organic matter incorporation cannot be described only by pore size distribution but rather may be better characterized by the pore's organization, i.e. pore connectivity and tortousity.

\subsection{Effective Water Conductive Porosity}

Effective porosity $\left(\theta_{\varepsilon}\right)$ was estimated by Equation (10) for the minimum equivalent radius of each class of pore size (Figure 6). Regardless of the treatment effect, macroand mesoporosity constituted a very small fraction of the total porosity. Water conductive macro- and mesoporosity of the field soil was improved with the incorporation of compost, straw and sawdust biomass. Especially, compost amendment increased the effective porosity by an order of magnitude compared with untreated soils (Figure 6). As it has been stated earlier, the underlying as- sumption in Equation (10) does not allow measuring the direct quantification of number of macro- and mesopores and effective porosity. Thus, the effective porosity measured in our experiment was an equivalent effective porosity. From Figure 6 the $\theta_{\varepsilon}$ increased not only for large macropores $(>0.50 \mathrm{~mm})$ but also for small mesopores compared with the non-amended soil. The average values of $\theta_{\varepsilon}$ with pores $>0.50 \mathrm{~mm}$ was $0.100 \%$ for compost, $0.090 \%$ for straw and $0.089 \%$ for sawdust amended soils. The $\theta_{\varepsilon}$ for macropores increased by $29.24 \%, 15.42 \%$ and $14.75 \%$, respectively for compost, straw and sawdust amended soil compared with the control. It is reported that, water conducting macropores often occupy $<1 \%$ of the total porosity [34]. On the other hand, The average values of $\theta_{\varepsilon}$ with pores $>0.25$ and $0.10 \mathrm{~mm}$ diameter (combined into mesopore class) occupied only $0.05 \%$, $0.02 \%$ and $0.03 \%$ of the total pore volume for compost, straw and sawdust amended soils, respectively. The increase in $\theta_{\varepsilon}$ was consistent with the increase of $K_{f s}$ (Figure 3) and the number of macropores (Table 1).

Table 2. Mean values of mean soil water potential $\left(\lambda_{c} ; \mathrm{m} / \mathrm{m}\right)$ and characteristic mean pore radius $\left(\lambda_{m} ; \mathrm{mm}\right)$ measured in all treatment plots. Treatment levels are defined in materials and methods.

\begin{tabular}{cccc}
\hline Treatment & Macro & $\lambda_{c}(\mathrm{~m} / \mathrm{m})$ & $\lambda_{m}(\mathrm{~mm})$ \\
\hline \multirow{3}{*}{$15.0-6.0$} & Control & 60 & 0.12 \\
& Compost & 50 & 0.15 \\
& Straw & 45 & 0.16 \\
& Sawdust & 48 & 0.15 \\
$6.0-3.0$ & Control & 27.3 & 0.27 \\
& Compost & 17.8 & 0.41 \\
& Straw & 26.2 & 0.28 \\
& Sawdust & 25.5 & 0.29 \\
\hline
\end{tabular}

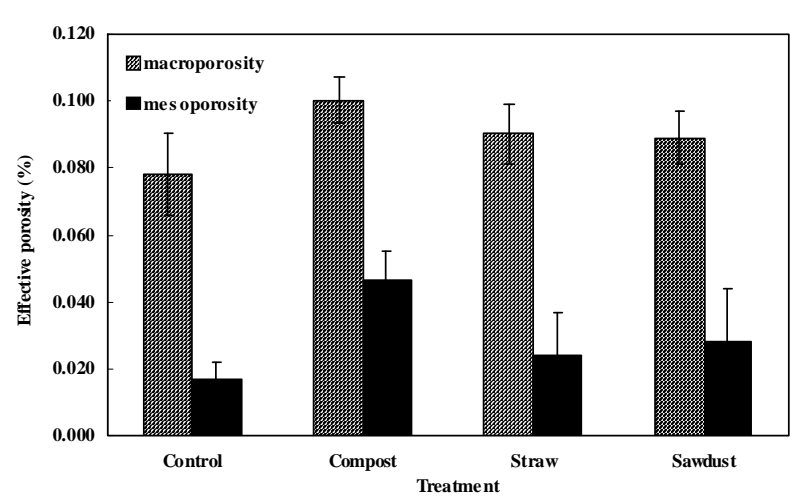

Figure 6. Effective porosity calculated as the percentage of total porosity for each pore class at the soil surface for compost, straw and sawdust amended soils. Vertical bars represent the standard deviation. 
The increase in water transmission pores probably developed channels in the soil layers with the ease of decomposition. We assumed that the decomposition of compost is relatively faster than straw and sawdust due to its compositional characteristics. Organic matter interaction with soil particles formed organo-mineral complexes, coupled with physical stress, improves soil aggregation [35-37]. Thus, the $\theta_{\varepsilon}$ for compost incorporated soil was higher than straw and sawdust. This improvement of soil aggregation leads to increase inter- and intra-aggregate spaces, which are responsible for water conductive porosity. Thus, the addition of biomass would favor soil water movement and drainage by increasing effective macro- and mesoporosity.

\subsection{Functional Porosity}

Functional porosity characterized by characteristic mean pore radius $\left(\lambda_{m}\right)$ estimated from the infiltration data for amendment treatments and control soils are presented in Table 2. Functional porosity was affected by biomass amendment, particularly pores in the range of 0.25 to $0.50 \mathrm{~mm}$ equivalent pore radius $\left(r_{e q}\right)$. However, small pores $(<0.10 \mathrm{~mm})$ were rarely modified by the incorporation of compost, straw and sawdust. The mean values of $\lambda_{m}$ increased for all treatment plots compared with the control at near saturated condition, i.e., at pressure head range of 6 to $3 \mathrm{~cm}$ of water. In contrast, $\lambda_{m}$ for lowpressure head remained almost constant for compost, straw and sawdust amended soil. Among all the amendments, the mean value of $\lambda_{m}$ increased by $51.9 \%$ at near saturated condition in the compost-amended soils compared with the control soils. The flow weighted mean soil water potential $\left(\lambda_{c}\right)$ indicated the relative magnitude of capillary and gravity forces acting in water transmission at different pressure head range in treatment plots (Table 2). The mean value of $\lambda_{c}$ was higher in control soils than biomass amended soils. The lower value of $\lambda_{c}$ in compost, straw and sawdust amended soils indicated that the water movement was mainly dominated by gravity, which was consistent with the increase of $K$ both at unsaturated and saturated condition. The higher values of $\lambda_{m}$ at all pressure head range showed that the pores hydraulically functioning were larger in amended soils compared with the control soils. This increase of $\lambda_{m}$ in the compost, straw and sawdust amended soils increased the K (Figure 3) relative to the control soil, particularly at saturated condition. The increase of $\lambda_{m}$ with the corresponding decrease of $\lambda_{c}$ in the biomass amended soils probably is linked to the substantial increase in number of macro- and mesopores per unit area (Table 1).

\section{Conclusion}

Application of compost, straw and sawdust to a clay loam soil generally affected the soil hydraulic and pore characteristics. Addition of biomass increased the water retention characteristics, hydraulic conductivity, number of macro- and mesoporosity and contribution of pores to the saturated water flux. Macro and mesopores contribution to the saturated water flux was evaluated from the water retention and hydraulic conductivity measurement. Remarkable difference was observed between these two methods, which were explained by the governing flow process. A new weighed factor $\left(W_{e}\right)$ was proposed assuming a better estimation of actual contribution of each pore class to saturated flux. Addition of organic biomass increased the number of macro- and mesopores per unit area. Improvement of this pore system is important for water movement and drainage. In all amended soils macroporosity yielded the highest percentage of the total effective porosity and accordingly increased near saturated conductivity. Analysis of the functional pores characteristics indicated that movement of water in the organic matter amended soils was dominated by gravity and the pores were hydraulically active. This study should further be evaluated to observe the plant response of organic biomass amendment and the consequent changes of soil hydraulic and pore characteristics.

\section{Acknowledgements}

We would like to thank to the Ministry of Education, Science, Sports and Culture, Japan for providing the financial support to this study through a graduate student scholarship. We are grateful to Ms. Mayumi Sugata and Ms. Akiko Sato for their help in the field measurements.

\section{REFERENCES}

[1] J. M. Tisdall and J. M. Oades, "Organic Matter and Water Stable Aggregate in Soils," Soil Science, Vol. 33, No. 2, 1982, pp. 141-163. doi:10.1111/j.1365-2389.1982.tb01755.x

[2] D. A. Martens and W. T. Frankenberger, "Modification of Infiltration Rates in a Organic-Amended Irrigated Soil," Agronomy Journal, Vol. 84, No. 4, 1992, pp. 707-717. doi:10.2134/agronj1992.00021962008400040032x

[3] A. C. Mathers and B. A. Stewart, "Manure Effects on Crop Yields and Soil Properties," Transaction of the American Society of Agricultural Engineers, Vol. 27, 1984, pp. 10221026.

[4] C. A. Campbel, M. Schnitzer, J. W. B., Stewart, V. O. Biederbeck and F. Selles, "Effect of Manure and P Fertilizer on Properties of a Black Chernozem in Southern Saskatchewan," Canadian Journal of Soil Science, Vol. 66, 1986, pp. 601-614.

[5] S. H. Anderson, C. J. Gantzer and J. R., Brown, "Soil Physical Properties after 100 Years of Continuous Cultivation," Soil and Water Conservation, Vol. 45, 1990, pp. 117-121. 
[6] M. R. Seashore, "Clinical, Biochemical and Nutritional Aspects of Trace Elements," Alan R. Liss, Inc., New York, 1982, pp. 5-15.

[7] R. Khaleel, K. R. Reddy and M. R. Overcash, "Changes in Soil Physical Properties Due to Organic Waste Additions: A Review," Journal of Environmental Quality, Vol. 10, 1981, pp. 133-141.

[8] J. K. Wu, "Two Problems of Computer Mechanics Program System," Proceedings of Finite Element Analysis and $C A D$, Peking University Press, Beijing, 1994, pp. 9-15.

[9] D. K. Benbi, C. R. Biswas, S. S. Bawa and K. Kumer, "Influence of Farmyard Manure, Inorganic Fertilizers and Weed Control Practices on Some Physical Properties in a Long-Term Experiment," Soil Use and Management, Vol. 14 , No. 1, 1998, pp. 52-54. doi:10.1111/j.1475-2743.1998.tb00610.x

[10] A. A. R. Hafez, "Comparative Changes in Soil Physical Properties Induced by Admixtures of Manures from Various Domestic Animals," Soil Science, Vol. 118, No. 1, 1974, pp. 53-59. doi:10.1097/00010694-197407000-00010

[11] J. J. Miller, N. J. Sweetland and C. Chang, "Hydrological Properties of a Clay Loam Soil after Long-Term Cattle Manure Application," Journal of Environmental Quality, Vol. 31, No. 3, 2002, pp. 989-996. doi:10.2134/jeq2002.0989

[12] G. A. Lehrsch and C. W. Robbins, "Cheese Whey Effects on Surface Soil Hydraulic Properties," Soil Use and Management, Vol. 12, No. 4, 1996, pp. 205-208. doi:10.1111/j.1475-2743.1996.tb00544.x

[13] M. Boyle, W. T. Frankenberger Jr. and L. H., Stolzy, "The Influence of Organic Matter on Soil Aggregation and Water Infiltration," Journal of Production Agriculture, Vol. 2, 1989, pp. 290-299.

[14] P. Schjonning, B. T. Christensen and B. Carstensen, "Physical and Chemical Properties of a Sandy Loam Receiving Animal Manure, Mineral Fertilizer or No Fertilizer for 90 Years," European Journal of Soil Science, Vol. 45, No. 3, 1994, pp. 257-268. doi:10.1111/j.1365-2389.1994.tb00508.x

[15] D. A. Rose, "The Effect of Long-Continued Organic Manuring on Some Physical Properties of Soils," In: W. S. Wilson, Ed., Soil Organic Matter Research: The Impact of Agriculture and the Environment, The Royal Chemical Society, Cambridge, 1991, pp. 197-205.

[16] M. Pagliai, M. La Marca and G. Lucamante, "Changes in Soil Porosity in Remolded Soils Treated With Poultry Manure," Soil Science, Vol. 144, No. 2, 1987, pp. 128140. doi:10.1097/00010694-198708000-00007

[17] I. Messing and N. J. Jarvis, "Temporal Variation in the Hydraulic Conductivity of a Tilled Clay Soil as Measured by Tension Infiltrometers," Soil Science, Vol. 44, No. 1, 1993, pp. 11-24. doi:10.1111/j.1365-2389.1993.tb00430.x

[18] R. A. Wooding, "Steady Infiltration from a Shallow Circular Pond," Water Resources Research, Vol. 4, No. 6, 1968, pp. 1259-1273. doi:10.1029/WR004i006p01259
[19] W. R. Gradner, "Some Steady-State Solutions for the Unsaturated Moisture Flow Equation with Application to Evaporation from a Water Table," Soil Science, Vol. 85, No. 4, 1958, pp. 228-232. doi:10.1097/00010694-195804000-00006

[20] D. E. Elrick, W. D. Reynolds, N. Baumgartner, K. A. Tan and K. L. Bradshaw, "In Situ Measurements of Hydraulic Properties of Soil Using the Guelph Permeameter and the Guelph Infiltrometer," 1987.

[21] M. D. Ankeny, M. Ahmed, T. C. Kasper and R. Horton, "Simple Field Method For Determining Unsaturated Hydraulic Conductivity," Soil Science Society of America Journal, Vol. 55, No. 2, 1991, pp. 467-470. doi:10.2136/sssaj1991.03615995005500020028x

[22] N. J. Jarvis and I., Messing, "Near-Saturated Hydraulic Conductivity in Soils of Contrasting Texture Measured by Tension Infiltrometers," Soil Science Society of America Journal, Vol. 59, No. 1, 1995, pp. 27-34. doi:10.2136/sssaj1995.03615995005900010004x

[23] K. W. Watson and R. J. Luxmoore, "Estimating Macroporosity in a Forest Watershed by Use of a Tension Infiltrometer," Soil Science Society of America Journal, Vol. 50, No. 3, 1986, pp. 578-582. doi:10.2136/sssaj $1986.03615995005000030007 \mathrm{x}$

[24] M. R. Cameria, R. M. Fernando and L. S. Pereira, "Soil Macropore Dynamics Affected by Tillage and Irrigation for a Silty Loam Alluvial Soil in Southern Portugal," Soil and Tillage Research, Vol. 70, No. 2, 2003, pp. 131-140. doi:10.1016/S0167-1987(02)00154-X

[25] R. Angulo-Jaramillo, J. P. Vandervaere, S., Roulier, J. P. Gaudet and M. Vauclin, "Field Measurement of Soil Surface Hydraulic Properties by Disc and Ring Infiltrometers: A Review and Recent Developments," Soil and Tillage Research, Vol. 55, No. 1-2, 2000, pp. 1-29. doi:10.1016/S0167-1987(00)00098-2

[26] R. Philip, "The Infiltration Joining Problem," Water Resources Research, Vol. 23, No. 12, 1987, pp. 2239-2245. doi:10.1029/WR023i012p02239

[27] P. A. C. Raats and W. R. Gardner, "Comparison of Empirical Relationships between Pressure Head and Hydraulic Conductivity and Some Observations on Radially Symmetric Flow," Water Resources Research, Vol. 7, No. 4, 1971, pp. 921-928. doi:10.1029/WR007i004p00921

[28] K. M. Perroux and I. White, "Design For Disc Permeameters," Soil Science Society of America Journal, Vol. 52, No. 5, 1988, pp. 1205-1215. doi:10.2136/sssaj1988.03615995005200050001x

[29] D. Hillel, "Introduction to Soil Physics," Academic Press, Orlando, 1982, pp. 59-73.

[30] R. J. Haynes and R. Naidu, "Influence of Lime, Fertilizer and Manure Applications on Soil Organic Matter Content and Soil Physical Condition: A Review," Nutrient Cycling in Agroecosystem, Vol. 51, No. 2, 1998, pp. 123137. doi:10.1023/A:1009738307837

[31] N. C. Brady, "The Nature and Properties of Soils," MacMillan Publishers Corporation, New York, 1974, pp. 2033.

[32] R. J. Luxmoore, "Micro-, Meso-, and Macroporosity of 
Soil," Soil Science Society of America Journal, Vol. 45, No. 3, 1981, pp. 671-672.

doi:10.2136/sssaj1981.03615995004500030051x

[33] P. Schjonning, "Effect of Incorporation of Straw and Soil Tillage," Tidsskrift for Planteavl, Vol. 89, 1985, pp. 425433.

[34] J. Bouma, "Influence of Soil Macroporosity on Environmental Quality," Advances in Agronomy, Vol. 46, 1991, pp. 1-34. doi:10.1016/S0065-2113(08)60577-5

[35] R. J. MacRae and G. R. Mehuys, "Effect of Green Manuring in Rotation with Corn on Physical Properties of
Two Quebec Soils," Biology, Agriculture and Horticulture, Vol. 4, No. 4, 1987, pp. 257-270. doi:10.1080/01448765.1987.9755112

[36] C. E. Clap, S. A. Stark, D. E. Clay and W. E. Larson, "Sewage Sludge Organic Matter and Soil Properties," Developments in Plant and Soil Sciences, Vol. 25, 1986, pp. 209-253.

[37] Y. Chen and Avnimelech, "The Role of Organic Matter in Modern Agriculture," Martinus Nijhoff Publishers, Dordrecht, 1986. 